work was implemented under the theme 'work on participatory methods in health' in the Regional Network for Equity in Health in East and Southern Africa (EQUINET) with support from SIDA Sweden.

\section{References}

Kiima, D. M., Njenga, F. G., Okonji, M. M. O., et al (2004) Kenya mental health country profile. International Review of Psychiatry, 16, 48-53.
Loewenson, R., Kaim, B., Mbuyita, S., et al (2006) Participatory Methods for People Centred Health Systems: A Toolkit for PRA Methods. TARSC, Ifakara (Harare).

Wadsworth, Y. (1998) What is participatory action research? Action Research International, Paper 2. Available at http://www.scu.edu.au/schools/gcm/ ar/ari/p-ywadsworth98.html (last accessed November 2008).

World Health Organization (2001) The World Health Report: mental disorders affect one in four people. Available at http://www.who. int/whr/2001/media_centre/press_release/en/index.html (last accessed November 2008)

\title{
Psychiatric practice for intellectual disability in the USA: challenges and advances
}

\section{Stephen Ruedrich MD}

Associate Professor of Psychiatry, Case School of Medicine, MetroHealth Medical Center, 2500 MetroHealth Drive, Cleveland, Ohio 44109, USA, email sruedrich@metrohealth.org

\begin{abstract}
ndividuals with intellectual disability are thought to make up at least $1 \%$ of the population, and it is estimated that approximately one-third of them have a comorbid psychiatric disorder (Harris, 2006). These 'dually diagnosed' individuals present a particular diagnostic and therapeutic challenge. A difficulty facing psychiatry in the USA over the past several decades has been to interest and educate a sufficient number of psychiatrists to meet the mental health needs of this group of patients (Department of Health and Human Services, 2002).

Most individuals with the dual diagnosis of intellectual disability and psychiatric disorder live in community settings, with families, or in small congregate facilities such as group homes, or in individual apartments with supported living assistance (Harris, 2006). Even at a peak in the mid-1960s, only about 190000 of the estimated three million persons with intellectual disability resided in large institutional settings in the USA, and over the past 40 years this number has shrunk to about 40000 (Prouty et al, 2007). Some states have completely closed such large institutions, and all states have focused on keeping persons with intellectual disability living and working in their own communities. This evolution to primarily community-based care has increased the need for adequate psychiatric services in both rural and urban settings, and provided an impetus for expanded education.
\end{abstract}

\section{The challenges}

Unfortunately, this need goes largely unmet, as there are insufficient numbers of psychiatrists with education, experience and skills in this area. In a 1965 survey conducted by the American Psychiatric Association (APA), 144 of 16500 psychiatrists (nearly 1\%) identified intellectual disability as their main area of work (Whiting, 1969). Since then, interest in the psychiatry of intellectual disability has seemingly attenuated in the USA, at least as revealed by membership and participation in professional organisations dedicated to this specialty. The National Association for the Dually Diagnosed (NADD), perhaps the US group most closely allied with dual diagnosis issues, has fewer than 100 psychiatrist members, and some of them are from outside the USA (NADD, 2007). Other professional organisations have similar or smaller numbers of psychiatrists who identify intellectual disability as their professional focus.

One possible reason for this lack of interest is confusion regarding whether the care of persons with intellectual disability and dual diagnosis should be the province of general psychiatry, or whether post-residency specialised training and certification in intellectual disability should be provided. Currently, the Residency Review Committee (RRC) for Psychiatry of the Accreditation Council for Graduate Medical Education (ACGME) in the USA provides no specific requirement for education in intellectual disability in general psychiatric training programmes (ACGME, 2007). This means many or even most general psychiatrists have little or no exposure to, or experience with, persons with intellectual disability during general residency education.

The situation is little better with regard to post-residency specialised training. Only in child and adolescent psychiatry fellowship training does the RRC for Psychiatry mention any need for specialised education: 'There must be an organized teaching and clinical experience in pediatric neurology, mental retardation, and other developmental disorders' (ACGME, 2007). However, the American Board of Psychiatry and Neurology (ABPN) reports that, at present, there are no accredited post-residency fellowships in the psychiatry of intellectual disability in the USA (ABPN, 2007). Perhaps the closest equivalent is fellowship training in neurodevelopmental disabilities, which is considered a sub-specialty of neurology. The ABPN approved fellowship education in neurodevelopmental disabilities in 1999, and held the first qualifying examination in 2001 (ABPN, 2007). Applicants for the certifying examimation must complete 2 core years 
of paediatrics, followed by 4 years of neurology. There are currently seven ACGME-approved training programmes, and 55 fellows have been certified since 2001 (ABPN, 2007). Unfortunately, at present, there is no psychiatric pathway to an equivalent certification for intellectual disability and dual diagnosis in the USA (ACGME, 2007).

This situation can be contrasted with that found in the UK, where many senior house officers have experience in intellectual disability before admission to the Royal College of Psychiatrists, and intellectual disability is one of six sub-specialties recognised by the College. With regard to provision of service to individuals with intellectual disability, the College has recommended a ratio of one (sub-specialist) consultant in intellectual disability per 80000 population (Royal College of Psychiatrists, 2003). Extrapolating this number to the USA, with a population of just over 300 million, would require nearly 3800 psychiatrists practising in this clinical arena. These needs should be contrasted with the fewer than 100 self-identified psychiatrists in the USA who, through their connections to professional organisations, declare their interest in the psychiatry of intellectual disability (see above). In the USA, there is no formal sub-specialist credentialing or 'certification' in the psychiatry of intellectual disability. As a result, most psychiatric care of persons with intellectual disability and dual diagnosis is provided by generalist psychiatrists, a few with on-the-job experience, but most of whom feel inadequately prepared to treat these persons.

\section{Positive developments}

There are, however, several positive developments in the psychiatry of intellectual disability in the USA that may ultimately provide the impetus for reversing these trends. The first is the change that has taken place recently in recharacterising 'mental retardation' as 'intellectual disability', with the hope of further destigmatising persons with this particular challenge (Schalock et al, 2007). Over the past 200 years, the method of identifying and labelling individuals with intellectual disability has gone through a number of evolutions. Before the 1950s, pejorative terms were used, such as idiocy, imbecility and feeble-mindedness, all subsumed under the collective title of mental deficiency. After the Second World War, these were gradually replaced by the term mental retardation in the USA (Schalock et al, 2007). In the past 4 years, intellectual disability has replaced the term mental retardation in some official language, most notably in the President's Committee on People with Intellectual Disability (2003) and the American Association on Intellectual and Developmental Disabilities (2007). However, many jurisdictions continue to use the term mental retardation in designations of official state departments, and it appears in many statutes and laws, which may take much longer to adopt less stigmatising language (National Association of State Directors of Developmental Disabilities Services, 2007). This is in contrast to the UK, where the term mental handicap was replaced by learning disability in the early 1990s and where the term intellectual disability has recently been adopted by the Royal College of Psychiatrists.

A second positive development has been the recent introduction of a new psychiatric diagnostic system applicable to persons with intellectual disability (Royal College of Psychiatrists, 2001). It has long been recognised that, although psychiatric disorders in persons with intellectual disability are common, they are often not appropriately identified, and determining an accurate psychiatric diagnosis becomes especially difficult as the level of intellectual functioning declines (Harris, 2006). To address these needs, the NADD, in association with the APA, has developed a diagnostic manual for persons with intellectual disability, designed as an adaptation of DSM-IV (NADD, 2007). Officially titled the Diagnostic Manual for Intellectual Disability (DM-ID), the text offers a description of each psychiatric disorder, a review of relevant research, an evaluation of the strength of evidence and a discussion of the aetiology and pathogenesis of specific disorders, all followed by adaptations of the DSM-IV diagnostic criteria for persons with $\mathrm{mild} /$ moderate and severe/profound intellectual disability (NADD, 2007). DM-ID follows the introduction of the Diagnostic Criteria for Psychiatric Disorders for Use with Adults with Learning Disabilities/Mental Retardation (DC-LD) in the UK in 2001 by the Faculty for the Psychiatry of Learning Disability of the Royal College of Psychiatrists and the Penrose Society (Royal College of Psychiatrists, 2001). Both manuals introduce the important concept of behavioural phenotypes, which are based on observations that a particular genetic aetiology of intellectual disability is often associated with, or predictive of, a specific developmental and behavioural course (Harris, 2006).

Finally, recent effort in the USA has focused on the issue of healthcare disparity for individuals with intellectual disability. In 2002, the US Surgeon General sponsored a major conference and position paper entitled Closing the Gap: A National Blueprint for Improving the Health of Persons with Mental Retardation (Department of Health and Human Services, 2002). The report was based on the repeated observation that 'people with MR [mental retardation] had poorer health and far less access even to basic screening and corrective treatment for vision, hearing, and oral health problems than others; and that diagnosis and treatment of mental illnesses and other serious disorders in this population were often delayed, inadequate, or not provided at all.' The blueprint outlined six goals to address healthcare disparity, one of which involved increasing the training and availability of healthcare professionals working in the field of intellectual disability.

\section{Conclusions}

Although there has never been a more exciting time for research and practice in the broad area of intellectual disability, our field remains challenged to provide mental health services for the more than three million persons with intellectual disability living in the USA. Currently, there are insufficient numbers of educated and experienced psychiatrists to address this challenge. It is hoped that the advent of new and less stigmatising language, new evidence and consensus-based diagnostic and therapeutic approaches, and a new blueprint for improving health can reverse this situation.

\section{References}

ABPN (2007) Initial Certification in the Subspecialty of Neurodevelopmental Disability. See http://www.abpn.com (last accessed May 2007). 
ACGME (2007) See http://www.acgme.org/acWebsite/downloads/RRC (last accessed May 2007)

Department of Health and Human Services (2002) Closing the Gap: A National Blueprint to Improve the Health of Persons with Mental Retardation. See http://www.surgeongeneral.gov/topics/ mentalretardation/retardation.pdf (last accessed May 2007)

Harris, J. C. (2006) Intellectual Disability: Understanding Its Development, Causes, Classification, Evaluation, and Treatment. Oxford University Press. NADD (2007) See http://www.thenadd.org (last accessed May 2007).

National Association of State Directors of Developmental Disabilities Services (2007) See http://www.nasddds.org (last accessed May 2007).

Prouty, R., Coucouvanis, K. \& Lakin, K. C. (2007) State institution populations in 2006 less than $80 \%$ of 40 years earlier: 'real dollar' per person costs more than 10 times greater. Intellectual and Developmental Disability, 45, 143-145.
Royal College of Psychiatrists (2001) DC-LD: Diagnostic Criteria for Psychiatric Disorders for Use with Adults with Learning Disabilities/ Mental Retardation (Occasional paper OP48). See http://www.rcpsych. ac.uk/publications/collegereports/op/OP48.aspx.

Royal College of Psychiatrists (2003) Meeting the Mental Health Needs of Adults with a Mild Learning Disability (College report CR115). See http://www.rcpsych.ac.uk/publications/collegereports/cr/cr115.aspx.

Schalock, R. L., Luckasson, R. A., Shogren, K. A., et al (2007) The renaming of mental retardation: understanding the change to the term intellectual disability. Intellectual and Developmental Disabilities, $45,116-124$

Whiting, J. F. (1969) Psychiatric Services, Systems Analysis, and Manpower Utilization. American Psychiatric Association.

NEWS AND NOTES

\section{Training in primary care psychiatry and psychosocial rehabilitation in Mongolia}

Mongolia, with a population of over 2 million, has a per capita income of about US\$400, while doctors' salaries seldom exceed US\$1800 per annum. In mental health, some 120 psychiatrists are distributed in most of the 22 aimags, or provinces, but resources exclude the provision of basic mental health services to populations outside the provincial capitals. Vast areas of Mongolia have no mental health services, although feldshers and primary care doctors are more widely distributed in most districts.

With financial support from the Board of International Affairs, Dr Parameshvara Deva, Secretary of the Western Pacific Division, ran a training course in December 2008, for about 25 physicians, neurologists and psychiatrists, who will then train other doctors and feldshers throughout Mongolia.

\section{College contribution to the National Conference on Mental Health in Iraq}

On invitation from the Minister of Health for Iraq, a delegation from the Royal College of Psychiatrists attended the 3rd Iraqi National Mental Health Conference, held in Baghdad, 17-18 October 2008. The delegation, which included Mohammed Al-Uzri, Rizkar Amin and Mohammed Abbas, also took part in the workshops in preparation for the conference. The objective of the conference was to draft the Ministry of Health's strategy on mental health, and it achieved its objective of providing a vision for mental health services in Iraq. It was attended by more than 300 persons, including ministers and members of the Iraqi parliament, and attracted media attention. Holding this conference for the first time in Iraq since 2003 was itself an achievement and a milestone in the recovery of health services in Iraq. The role of the College was acknowledged by the health community in Iraq, as well as by international organisations working there.

\section{College's Faculty of the Psychiatry of Old Age}

The fact that UK mental health services discriminate against older people was confirmed in major reports published in 2007 and 2008. In the 'need not age' argument for the organisation and delivery of services, the College's Faculty of the Psychiatry of Old Age has been vocal in defending the right of older people to access services designed to meet their needs. With other professional and consumer organisations, the Faculty published a consensus statement about need and action in 2008 (see http://www. olderpeoplesmentalhealth.csip.org.uk). This is a global issue. The Faculty is strongly represented in the landmark National Dementia Strategy for England, which was due to be published in December 2008.

Following a jointly organised conference in Dublin in 2008, the College Faculty is now affiliated with the International Psychogeriatric Association. The conference in Barcelona in 2009 will involve members of the European Association and an international bursary has been created to help overseas psychiatrists attend these meetings. Closer links are being developed with the Indian section of old age psychiatry and the Royal Australian and New Zealand College of Psychiatrists.

The Faculty has produced a new training curriculum and its website receives substantially more hits than does any other Faculty of the College. The profile of older people's mental health has never been higher and the expansion of a specialism for older people never more important.

Dave Anderson

Chair, Faculty of the Psychiatry of Old Age, Royal College of Psychiatrists 